\title{
Analisis Tata Letak Pabrik dan Pola Aliran Bahan Feronikel di FeNi Plant 3 PT Antam Tbk Unit Bisnis Pertambangan Nikel Sulawesi Tenggara
}

\section{Analysis of Factory Layout and Floe Pattern of Ferronickel Material at FeNi 3 Plant PT Antam Tbk Southeast Sulawesi Nickel Mining Business Unit}

Taufiq Hidayat ${ }^{1 *}$, Heti Mulyati ${ }^{1}$, M Syaefudin Andrianto $^{1}$

1) Departemen Manajemen, Fakultas Ekonomi dan Manajemen IPB Kampus Dramaga Bogor 16680

\begin{abstract}
Nickel industry is one of the industry that potentially to increase foreign exchange. PT Antam Tbk UBPN Southeast Sulawesi has land area about 169.194,937 $\mathrm{m}^{2}$ with 14.452,85 $\mathrm{m}^{2}$ of buildings in FeNi Plant 3. In producing nickel, PT Antam Tbk UBPN Southeast Sulawesi requires a more optimum layout and material flow pattern. The objective of this research was to analyzed the layout of production and material handling in the FeNi Plant 3. The methods used in this study were relationship analysis of production activity and Assembly Line Balancing. The result showed that the current ferronikel flow layout and flow pattern is shaped a straight line, and efficiency assembly line balansing about 71,25 percent.
\end{abstract}

Keywords: assembly line balancing, ferronickel, material flow pattern, layout production.

\begin{abstract}
ABSTRAK
Industri pengolahan nikel merupakan salah satu industri yang berpotensi menambah devisa negara. PT Antam Tbk UBPN Sulawesi Tenggara memiliki luas lahan sekitar 169.194,937 $\mathrm{m}^{2}$ dengan luas bangunan di FeNi Plant 3 sekitar 14.452,85 $\mathrm{m}^{2}$. PT Antam Tbk UBPN Sulawesi Tenggara dalam memproduksi nikel memerlukan tata letak dan pola aliran bahan yang lebih optimum. Tujuan penelitian yaitu menganalisis tata letak produksi dan pola aliran bahan feronikel di FeNi Plant 3 serta efisiensi keseimbangan lini perakitan. Metode yang digunakan adalah observasi dan analisis hubungan kedekatan aktivitas produksi dan keseimbangan lini perakitan. Hasil penelitian menunjukkan tata letak dan pola aliran bahan feronikel saat ini berbentuk garis lurus, serta efisiensi keseimbangan lini perakitan sebesar 71,25 persen.
\end{abstract}

Kata kunci: feronikel, keseimbangan lini perakitan, pola aliran bahan, tata letak produksi.

*Corresponding author

Alamat e-mail: taufiqhidayatmujtahid@gmail.com 


\section{PENDAHULUAN}

Menurut Survei Geologi Amerika Serikat (USGS), Indonesia menduduki peringkat ke-6 sebagai negara yang kaya akan sumber daya tambang. Kondisi excellent tectonic dan geologi tersebut yang membawa Indonesia menjadi salah satu produsen terbesar emas, tembaga, nikel, dan timah. Oleh karena itu, Indonesia menjadi negara yang sangat menjanjikan bagi kalangan pelaku industri pertambangan untuk berinvestasi di Indonesia (Indonesian Mining Association 2014). Salah satu industri pertambangan yang strategis di Indonesia adalah nikel. Sumber daya nikel Indonesia diperkirakan mencapai 2.633 juta ton ore dengan cadangan sebesar 577 juta ton ore yang tersebar di Sulawesi, Kalimantan, Maluku dan Papua. Komoditi nikel dikelompokkan menjadi tiga, yaitu bijih nikel, feronikel dan nikel kasar, yang mana hampir seluruhnya dimanfaatkan untuk memenuhi kebutuhan ekspor. Selama periode tahun 2012-2014, ekspor bijih nikel mengalami fluktuasi pada setiap negara. Ekspor bijih nikel tertinggi ke negara Tiongkok pada tahun 2013 adalah sebesar 58.604.651,8 ton. Adapun produksi bijih nikel Indonesia mengalami penurunan pada periode 2012-2014, yaitu pada tahun 2013 mencapai 65.047.388 ton, tahun 2014 sebesar 39.034.912 ton, sedangkan pada tahun 2015 adalah sebesar 34.063.566 ton. Hal ini dapat dilihat pada Badan Pusat Statistik (2015).

Salah satu perusahaan yang memproduksi nikel di Indonesia adalah PT Antam Tbk Unit Bisnis Pertambangan Nikel (UBPN) Sulawesi Tenggara (Sultra) yang terletak di Pomalaa. Strategi utama PT Antam adalah bergerak ke arah hilir untuk menghasilkan produk-produk bernilai tambah. Produk-produk yang dihasilkan PT Antam UBPN Sultra adalah Feronikel dan Slag. Feronikel digunakan sebagai bahan baku untuk beragam industri seperti baterai, elektronik, industri antariksa, dan turbin gas; sedangkan slag digunakan untuk bahan bangunan (Antam 2016). PT Antam Tbk memiliki empat pabrik feronikel, yakni pabrik FeNi Plant I, pabrik FeNi Plant II, pabrik FeNi Plant III, dan pabrik FeNi Plant IV. Kapasitas terpasang di keempat pabrik tersebut adalah 26.000 ton Ni dengan mengasumsikan beban puncak $42 \mathrm{MW}$. FeNi Plant 3 masih terdapat sisa waktu produksi feronikel sebesar 4,85 jam dalam sehari produksi feronikel, selain itu belum ada penelitian tentang tata letak dan pola aliran bahan, serta efisiensi keseimbangan lini perakitan terhadap FeNi Plant 3.

Proses produksi nikel memerlukan fasilitas dengan tata letak yang optimum, terutama untuk mengalirkan bahan. Tata letak yang dianalisis engan baik dapat memaksmalkan kapasitas gudang (Hidayat 2012, Juliaanadan Handayani 2016). Pada saat ini, tata letak di PT Antam Tbk UBPN masih perlu dikaji lebih mendalam untuk pergerakan bahan dan manusia yang lebih efisisen. Tata letak yang efisien dan efektif, dapat menaikkan efisiensi produksi, pemanfaatan ruangan pabrik yang lebih baik, kegiatan pemindahan yang lebih sederhana, pemanfaatan peralatan yang lebih baik, mengurangi kecelakaan pabrik, proses penjadwalan lebih baik, serta urutan pekerjaan yang logis (Apple 1990). Desain tata letak pada dasarnya memiliki langkahlangkah yang dikategorikan ke dalam tiga tahapan, yaitu tahap analisis, penelitian, dan evaluasi alternatif tata letak. Tahap analisis mencakup analisis aliran bahan baku, analisis aktivitas, diagram hubungan aktivitas, pertimbangan keperluan ruangan, dan ruangan yang tersedia. Tahap yang kedua adalah tahap penelitian yang dimulai dari perencanaan diagram hubungan ruangan sampai dengan perancangan alternatif tata letak. Tahap terakhir adalah proses seleksi dengan jalan mengevaluasi alternatif tata letak yang telah dirancang (Saputra 2015). Tujuan dari penelitian yang dilakukan di PT Antam Tbk Unit Bisnis Pertambangan Nikel (UBPN) Sulawesi Tenggara (Sultra) adalah mengevaluasi tata letak produksi dan pola aliran bahan feronikel yang ada saat ini dan efisiensi keseimbangan lini perakitan tata letak pabrik yang ada saat ini.

\section{METODE PENELITIAN}

Lokasi dari penelitian ini adalah di PT Antam Tbk Unit Bisnis Pertambangan Nikel (UBPN) Sulawesi Tenggara, Kelurahan Pomalaa, Kecamatan Pomalaa, Kabupaten Kolaka, Provinsi Sulawesi Tenggara. Jenis data yang digunakan adalah data primer dan sekunder. Data primer dalam penelitian ini adalah data yang didapatkan dari survei lapang dan wawancara mendalam, sedangkan data sekunder adalah data yang didapatkan dari studi literatur.

Jurnal Manajemen dan Organisasi (JMO),

Vol. 9 No. 3 , Desember 2018, Hal. 173-180 
Metode pengolahan dan analisis data adalah menggunakan metode Penyeimbangan Lini Perakitan. Metode Penyeimbangan Lini Perakitan merupakan metode yang digunakan untuk meminimalkan ketidakseimbangan antara mesin atau karyawan dan memenuhi output yang dibutuhkan. Menurut Heizer dan Render (2005) langkah-langkah dalam menggunakan metode ini adalah sebagai berikut :

1. Menghitung unit yang dibutuhkan perhari (tingkat permintaan atau tingkat produksi) dan dibagi menjadi waktu produksi yang tersedia per hari. Operasi ini disebut juga waktu siklus (cycle time), yaitu waktu maksimal di mana produk dapat tersedia pada stasiun kerja jika tingkat produksi tercapai:

$$
x=\frac{\mathrm{y}}{\mathrm{z}}
$$

dimana, $\mathrm{x}=$ waktu siklus

$\mathrm{y}=$ waktu produksi yang tersedia per hari

$\mathrm{z}=$ unit yang diproduksi per hari

2. Menghitung jumlah stasiun kerja minimal. Jumlah ini merupakan waktu pengerjaan tugas total (waktu yang dibutuhkan untuk membuat produk) dibagi dengan waktu siklus. Pecahan dibulatkan pada nilai bulat terdekat yang lebih besar:

$$
\text { Jumlah stasiun kerja minimum }=\frac{\sum_{i=1}^{n} \text { Waktu pengerjaan tugas } i}{\text { Waktu siklus }}
$$

di mana, $n=$ jumlah tugas perakitan

3. Efisiensi keseimbangan lini perakitan. Efisiensi keseimbangan perakitan lini dapat dihitung dengan membagi waktu tugas total dengan jumlah stasiun kerja yang dibutuhkan dikalikan dengan waktu siklus:

$$
\text { Efisiensi }=\frac{\sum \text { Waktu pengerjaan tugas }}{\text { (jumlah stasiun kerja aktual) } \mathrm{x} \text { (waktu siklus) }}
$$

Menurut Faishol dan Hastuti (2013), dalam perancangan tata letak analisis hubungan aktivitas diperlukan untuk menentukan derajat kedekatan hubungan antar departemen dipandang dari dua aspek yaitu kualitatif dan kuantitatif. Aspek kualitatif akan lebih dominan dalam menganalisis derajat hubungan aktivitas dan biasanya ditunjukkan oleh pera hubungan aktivitas, sedangkan untuk aspek kuantitatif lebih dominan pada analisis aliran material, sehingga dalam membantu menentukan aktivitas yang harus diletakkan pada suatu departemen, telah ditetapkan suatu pengelompokan derajat hubungan, yang diikuti dengan tanda bagi setiap derajat tersebut. Berbagai hubungan tersebut dapat dilihat pada Tabel 1.

Tabel 1. Klasifikasi Hubungan Aktivitas Produksi

\begin{tabular}{lccc}
\hline \multicolumn{1}{c}{ Nilai } & Warna & Hubungan Kedekatan & Skor \\
\hline A (Absolute) & Merah & Mutlak perlu berdekatan & 6 \\
E (Especially) & Kuning & Sangat penting berdekatan & 5 \\
I (Important) & Hijau & Penting berdekatan & 4 \\
O (Ordinary) & Biru & Cukup penting berdekatan & 3 \\
U (Unimportant) & Putih & Tidak penting berdekatan & 2 \\
X (Undesirable) & Cokelat & Tidak dikehendaki berdekatan & 1 \\
\hline
\end{tabular}

Sumber : Lugito (2014)

Tabel 1 merupakan tabel dimana klasifikasi score dari masing masing hubungan kedekatan, dimana A (absolute) diestimasikan bernilai 6, E (Especially) bernilai 5 dan seterusnya, sehingga $\mathrm{X}$ (Undesirable) bernilai 1. Nilai atau simbol tersebut digunakan untuk membantu menentukan kedekatan antar tiap aktivitas produksi perusahaan. 
Tabel 2. Indikator Hubungan Aktivitas Produksi

\begin{tabular}{l}
\hline \multicolumn{1}{c}{ Indikator } \\
\hline Urutan aliran kerja \\
Derajat hubungan kepegawaian \\
Kemudahan pengawasan \\
Perpindahan alat atau karyawan \\
Alat informasi dan komunikasi yang sama \\
Karyawan yang sama \\
Bising, debu bau tidak sedap \\
Sumber: Wahyudi (2010)
\end{tabular}

Tabel 2 menunjukkan indikator yang digunakan untuk menentukan hubungan kedekatan antar tiap aktivitas produksi feronikel PT Antam Tbk UBPN Sultra, sehingga dapat dengan mudah menggambarkan dan menentukan simbol atau nilai kedekatan tersebut.

\section{HASIL DAN PEMBAHASAN}

\section{Gambaran Umum Perusahaan}

Unit Bisnis Pertambangan Nikel Sulawesi Tenggara (UBPN Sultra) merupakan salah satu dari empat unit bisnis utama yang dimiliki PT Antam Tbk UBPN Sultra terletak di Kecamatan Pomalaa yang secara administrasi berada di Kabupaten Kolaka, Sulawesi Tenggara Tenggara. Secara geografis, kecamatan Pomalaa terletak diantara $4^{0} 10^{\prime} 00^{\prime \prime}$ hingga $4^{\circ} 27^{\prime} 25^{\prime \prime}$ LS dan $121^{\circ} 31^{\prime} 30^{\prime \prime}$ hingga 121039'03" BT. Lokasi UBPN Sultra dapat dicapai dengan menggunakan transportasi udara dari Bandara Sultan Hasanuddin, Makassar ke Bandara Sangia Nibandera, Kecamatan Tanggetada Kolaka, dilanjutkan dengan perjalanan darat dari Kecamatan Tanggetada ke Kecamatan Pomalaa. Total waktu yang dibutuhkan untuk mencapai lokasi UBPN Sultra adalah sekitar 2 jam dengan rincian satu jam untuk perjalanan udara dan satu jam untuk perjalanan darat.

\section{Proses Produksi Feronikel}

Pengolahan feronikel di UBPN Sultra berlangsung melalui beberapa tahapan. Tabel 3 menunjukkan diagram proses produksi feronikel FeNi Plant 3. Aktivitas Storage diberi simbol segitiga, artinya bahwa Aktivitas Storage merupakan aktivitas yang berfungsi sebagai penyimpanan bahan baku produksi tersebut. Aktivitas Storage ke Aktivitas Ore Preparation menggunakan simbol arah, artinya bahwa setelah melalui Aktivitas Storage, kemudian bahan baku menggunakan alat transportasi truk pengangkut tanah yang mengandung nikel. Aktivitas Ore Preparation, Ore Bin, Kiln, Smelting, hingga Aktivitas Refinery menggunakan simbol lingkaran, artinya bahwa semua Aktivitas proses-proses tersebut masuk pada tahapan memproduksi feronikel tersebut.

Tabel 3. Diagram Proses Produksi Feronikel

\begin{tabular}{|c|c|c|c|}
\hline Jarak (m) & Waktu (dalam jam) & Simbol Diagram & Keterangan Proses \\
\hline & 1,5 & & Storage (I) \\
\hline 65,5 & 1 & & Ore Preparation (II) \\
\hline 97 & 0,5 & & Ore Bin (III) \\
\hline 69,8 & 2,4 & & Kiln (IV) \\
\hline 26,4 & 2,4 & & Smelting (V) \\
\hline 26,6 & 0,75 & & Refinery (VI) \\
\hline
\end{tabular}

Sumber: data diolah 2017

Jurnal Manajemen dan Organisasi (JMO),

Vol. 9 No. 3 , Desember 2018, Hal. $173-180$ 


\section{Analisis hubungan kedekatan aktivitas produksi feronikel}

Hubungan kedekatan dari masing-masing aktivitas pada bagan tersebut terlihat jelas bahwa setiap aktivitas memiliki hubungan yang beraneka ragam seperti tampak pada Gambar 1. Data diatas diambil dengan cara melihat indikator (pada Tabel 2) dan mewawancarai pembimbing magang di PT Antam Tbk UBPN Sultra.

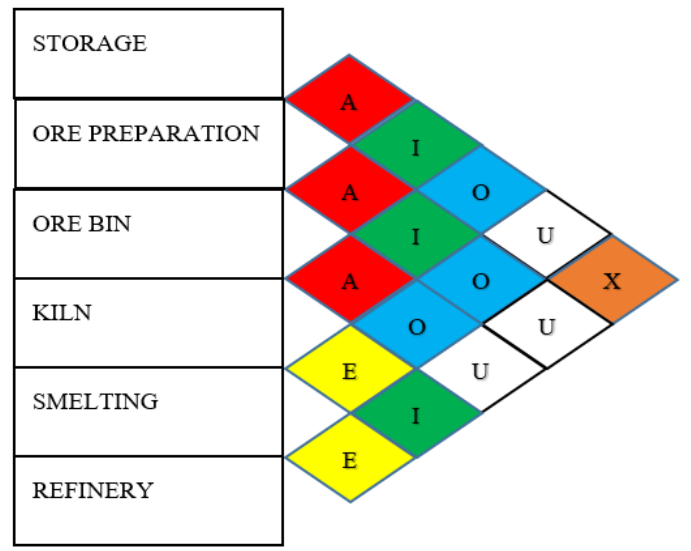

Gambar 1. Hubungan Kedekatan Aktivitas Produksi Feronikel Sumber: data diolah (2017)

Pada dasarnya mesin-mesin yang digunakan untuk memproduksi feronikel di FeNi Plant 3 PT Antam Tbk UBPN Sultra memiliki ukuran yang sangat besar, sehingga sulit untuk dipindahkan dan ditukarkan. Gambar 1 menunjukkan aktivitas atau proses Storage dan aktivitas Ore Preparation memiliki hubungan kedekatan dengan simbol A dan skor 6, artinya bahwa kedua aktivitas tersebut mutlak untuk didekatan dan dengan indikator urutan aliran kerja. Aktivitas Ore Preparation dan Ore Bin, serta aktivitas Ore Bin dan Kiln juga memiliki hubungan kedekatan dengan simbol A dan skor 6, artinya masing masing kedekatan tersebut mutlak untuk didekatkan, dengan indikator urutan aliran kerjanya. Aktivitas Kiln dan Smelting, serta aktivitas Smelting dan Refinery memiliki hubungan kedekatan dengan simbol E dan skor 5, artinya bahwa kedua aktivitas tersebut penting untuk didekatkan, dengan indikator urutan aliran kerja dan indikator perpindahan alat. Aktivitas Storage dan Ore Bin, Ore Preparation dan Kiln, serta aktivitas Kiln dan Refinery memiliki hubungan kedekatan dengan simbol I dan skor 4, artinya bahwa aktivitasaktivitas tersebut penting berdekatan, dengan indikator perpindahan alat atau karyawan, kemudahan pengawasan. Aktivitas Storage dan Kiln, Ore Preparation dan Smelting, serta aktivitas Ore Bin dan Smelting memiliki hubungan kedekatan dengan simbol O dan skor 3, artinya bahwa aktivitas-aktivitas tersebut cukup penting berdekatan, dengan indikator urutan aliran kerja, perpindahan alat, serta posisi dari mesin-mesin tiap aktivitas yang tidak memungkinkan untuk diubah. Aktivitas Storage dan Smelting, Ore Preparation dan Refinery, serta Aktivitas Ore Bin dan Refinery memiliki hubungan kedekatan dengan simbol U dan skor 2, artinya bahwa aktivitasaktivitas tersebut tidak penting berdekatan, dengan indikator urutan aliran kerja, tidak memudahkan pengawasan, perpindahan alat yang sulit dilakukan, serta posisi mesin-mesin tiap aktivitas yang tidak memungkinkan untuk diubah. Aktivitas Storage dan Refinery memiliki hubungan kedekatan dengan simbol $\mathrm{X}$ dan skor 1, artinya bahwa kedua akivitas tersebut tidak dikehendaki untuk berdekatan, hal ini berdasarkan indikator urutan aliran kerja yang berjauhan, mengalami kesulitan pengawasan, perpindahan alat atau karyawan yang sulit.

\section{Analisis tata letak dan pola aliran bahan feronikel}

Analisis aliran material merupakan analisis pengukuran kuantitatif untuk setiap gerakan

Jurnal Manajemen dan Organisasi (JMO),

Vol. 9 No. 3 ,

Desember 2018, Hal. $173-180$ perpindahan material di antara aktivitas-aktivitas operasional. Pola aliran ini menggambarkan material masuk sampai pada produk jadi. PT Antam UBPN Sulawesi Tenggara ini menggunakan pola aliran bentuk garis lurus (Gambar 2). 


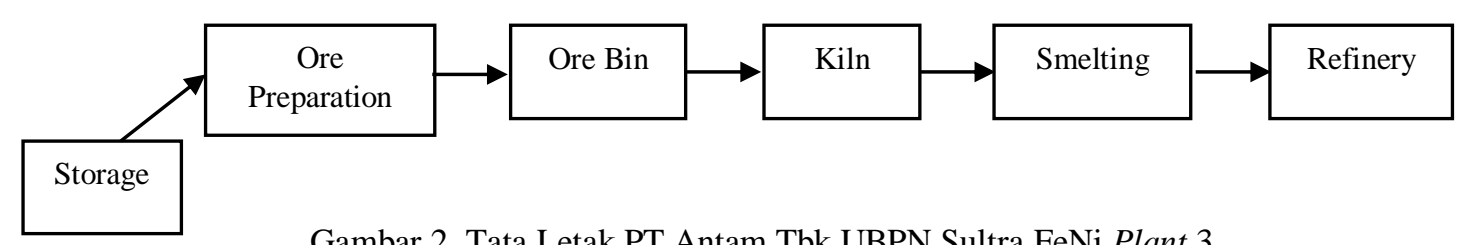

Gambar 2. Tata Letak PT Antam Tbk UBPN Sultra FeNi Plant 3

Sumber: data diolah (2017)

PT Antam Tbk UBPN Sultra cenderung memiliki pola aliran bahan berbentuk garis lurus. Hal ini dapat dilihat jelas dengan menggunakan perangkat lunak POM for windows 5. Pola aliran bahan yang berbentuk garis lurus dapat digunakan pada perusahaan berbasis produk. PT Antam Tbk UBPN Sultra memiliki ciri dan karakteristik perusahaan berbasis produk, seperti memiliki mesin yang paling baik, produksi yang kontinu, serta memiliki produk bervolume tinggi.

Efisiensi eseimbangan Lini Perakitan tata letak PT Antam Tbk UBPN Sultra terdiri atas waktu siklus produksi feronikel, jumlah stasiun kerja minimum, dan efisiensi keseimbangan lini perakitan, dapat dilihat pada Tabel 4.

Tabel 4. Keseimbangan Lini Perakitan PT Antam UBPN Sultra FeNi Plant 3

\begin{tabular}{lccc}
\hline \multicolumn{1}{c}{ Stasiun } & Aktivitas & Waktu (jam) & Waktu Sisa (jam) \\
\multicolumn{1}{c}{1} & Storage & 1,5 & 0,9 \\
\multicolumn{1}{c}{ Ore Preparation } & 1 & 1,4 \\
\multicolumn{1}{c}{ Ore Bin } & Kiln & 0,5 & 0,9 \\
& Smelting & $2,4^{*}$ & 0 \\
\multicolumn{1}{c}{ Refinery } & $2,4^{*}$ & 0 \\
\hline Ringkasan statistik & & 0,75 & 1,65 \\
\hline Waktu siklus & 2,4 & jam & \\
Stasiun minimal & 4 & & \\
Stasiun aktual & 5 & & \\
Alokasi waktu & 12 & jam/siklus & \\
Waktu yang dibutuhkan & 8,55 & jam/unit & \\
Waktu luang & 3,45 & jam/siklus & \\
Efisiensi & $71,25 \%$ & & \\
Keseimbangan penundaan & $28,75 \%$ & & \\
\hline
\end{tabular}

*) estimasi

Sumber: data diolah (2017)

Tabel 4 menunjukkan hasil dari perhitungan pengerjaan tiap proses produksi dengan waktu siklus sebesar 2,4 jam/ton yang didapatkan dari hasil pembagian 24 jam waktu produksi yang tersedia per hari dibagi dengan 10 ton unit produksi perhari. Produksi 10 ton per hari didapatkan dari estimasi total produksi tahunan sebesar 14.600 ton, yang dibagi 365 hari kemudian dibagi menjadi 4 FeNi Plant tersebut. FeNi Plant 3 memiliki enam stasiun kerja, hal ini dapat dilihat dari stasiun kerja pertama, yaitu Storage. Storage menghabiskan waktu 1,5 jam pengerjaan dan memiliki 0,9 jam waktu kosong dari waktu siklusnya. Stasiun kerja kedua, yaitu Ore Preparation dan Ore Bin. Ore Preparation menghabiskan waktu 1 jam pengerjaan dan memiliki 1,4 waktu kosong, serta Ore Bin menghabiskan 0,5 jam pengerjaan dan memiliki 0,9 waktu kosong. Stasiun kerja ketiga, yaitu Kiln menghabiskan 2,4 jam pengerjaan dan tidak memiliki waktu kosong dari waktu siklusnya. Stasiun kerja keempat, yaitu Smelting menghabiskan 2,4 jam pengerjaan serta tidak memiliki waktu kosong dari waktu siklusnya. Stasiun kerja kelima, yaitu Refinery menghabiskan 0,75 jam pengerjaan dan memiliki 1,65 waktu kosong. Perusahaan dalam memproduksi feronikel membutuhkan 8,55 jam dan memiliki 3,45 jam waktu yang terbuang dalam satu hari produksi, serta memiliki efisiensi keseimbangan lini perakitan sebesar 71,25 persen, artinya bahwa dalam memproduksi 10 ton per hari dengan waktu pengerjaan produksi feronikel sebanyak 8,55 jam, mampu memaksimalkan efisiensi keseimbangan lini perakitan sebesar 71,25 persen terhadap tata letak di FeNi Plant 3. Perusahaan dalam mengoptimalkan

Jurnal Manajemen dan Organisasi (JMO), Vol. 9 No. 3 , Desember 2018, Hal. $173-180$ 
waktu sisa hasil produksi dapat dilakukan dengan cara meningkatkan jumlah produksi feronikel harian, sehingga waktu siklus menurun dan menyebabkan waktu sisa produksi dapat berkurang. Selain itu, perusahaan juga dapat memaksimalkan pemakaian mesin produksi, sehingga waktu yang dibutuhkan untuk memproduksi feronikel meningkat pada masing-masing aktivitas produksi, sehingga waktu sisa pengerjaaan produksi feronikel dapat menurun.

\section{Implikasi Manajerial}

Implikasi manajerial terhadap tata letak dan pola aliran bahan feronikel, serta efisiensi keseimbangan lini perakitan untuk perusahaan dilakukan menggunakan pendekatan POAC, yaitu Planning, Organizing, Action, dan Controlling. Berikut implikasi manajerial berdasarkan pendekatan tersebut :

\section{Planning}

PT Antam Tbk memiliki satuan kerja yang saling mendukung satu sama lain untuk memproduksi feronikel, mengefisiensikan keseimbangan lini perakitan untuk memproduksi feronikel, serta mengoptimalkan tata letak dan pola aliran bahan yang sudah ada, sehingga dapat memaksimalkan keuntungan perusahaan dan mencapai target yang diberikan oleh direksi perusahaan. Perencanaan tersebut dapat dilakukan dengan cara mengkolaborasikan dan mengkoordinasikan satuan kerja Civil Planning Departement dengan Processing and Engineering Departement yang berkaitan dengan produksi dan tata letak pabrik tersebut.

\section{Organizing}

Pengorganisasian dapat dilakukan perusahaan dengan mengevaluasi Sumber Daya Manusia (SDM) yang berkompetensi untuk ditempatkan sesuai bidang kerja masing-masing. Evaluasi SDM tersebut dilakukan dengan cara membuat Penempatan SDM yang tepat akan meningkatkan kinerja perusahaan, serta meningkatkan keuntungan serta efektifitas perusahaan.

3. Action

Pelaksanaan efisiensi keseimbangan lini perakitan, serta mengoptimalkan tata letak dan pola aliran bahan tersebut dapat dilakukan dengan baik jika masing-masing karyawan perusahaan berperan aktif dalam melakukan pengarahan dari masing-masing pimpinan tiap satuan kerja tersebut. Peningkatan kesadaran karyawan dilakukan dengan cara memberikan pelatihan yang berkaitan dengan tata letak,, workshop, dan insentif, sehingga karyawan dapat meningkatkan produktifitas kerja.

\section{Controlling}

Perusahaan dapat melakukan pengawasan terhadap seluruh karyawan, mesin yang digunakan untuk memproduksi feronikel, serta ketersediaan bahan baku feronikel. Pengawasan tersebut dilakukan bertahap dan konsisten, agar dapat diketahui sampai dimana produktifitas karyawan, umur mesin, serta seberapa banyak ketersediaan bahan baku tersebut. Satuan kerja Civil Planning Department melakukan pengawasan dan pelaporan progres kerja pada saat rapat kerja harian yang dipimpin langsung oleh Manajer Civil Planning Deparment. Hal ini dapat menjadi contoh untuk satuan kerja lainnya untuk menerapkan pengawasan dan pelaporan progres tersebut.

\section{KESIMPULAN}

PT Antam Tbk UBPN Sultra sudah merancang tata letak dan pola aliran bahan feronikel dengan baik, hal ini dilihat dari tata letak yang berbasis produksi serta pola aliran yang berbentuk garis lurus, di mana FeNi Plant 3 memiliki volume produksi yang tinggi dan menggunakan peralatan dan mesin khusus. Feni Plant 3 memiliki lima stasiun kerja aktual dengan memberikan kesetaraan waktu produksi feronikel. Hasil menunjukkan bahwa terdapat 8,55 jam waktu pengerjaan dengan 3,45 jam waktu yang terbuang, serta memiliki 71,25 persen efisiensi keseimbangan lini perakitan. 


\section{DAFTAR PUSTAKA}

Antam. (2016). Pengolahan Feronikel [internet]. [diunduh pada tahun 2017]. Tersedia pada: http//www.antam.com/index.php?option=com_content\&task=view\&id=30\&Itemid=36\&l ang=id

Apple, J. M. (1990). Plant Layout and Material Handling. Terjemahan Bandung: Institut Teknologi Bandung.

Faishol, M., \& Hastuti, S. (2013). Perancangan Ulang Tata Letak Fasilitas Produksi Pabrik Tahu Srikandi Junok Bangkalan, 7(2). Madura: Universitas Trunojoyo Madura.

Hidayat, N. P. A. (2012). Perancangan Tata Letak Gudang dengan Metoda Class Based Storage Studi Kasus CV SG Bandung. Jurnal Al-Azhar Indonesia, 1(2).

Heizer, J., \& Render, B. (2005). Operations Management Manajemen Operasi. Terjemahan. Jakarta: Salemba Empat.

Indonesian Mining Association. (2014). Potensi dan Tantangan Pertambangan Indonesia [internet]. [diunduh pada tanggal 28 Februari 2018]. Tersedia pada: https://www.imaapi.com/index.php?option=com_content $\&$ view=article \&id=1937:potensi-dan-tantanganpertambangan-di-indonesia\&catid=47:media-news\&Itemid=98\&lang=id

Juliana, H., \& Handayani, N. U. (2016). Peningkatan Kapasitas Gudang dengan Perancangan Lay Out Menggunakan Metode Class Based Storage. Jurnal Teknik Industri, XI(2).

Lugito, A. W., Oktiarso, T. (2014). Perancangan Tata Letak yang Optimal Menggunakan Algoritma Corelap dan Metode Graph-Based Construction, 1(1).

Saputra, N. A. E. (2015). Resign Tata Letak Fasilitas Produksi Dalam Meningkatkan Efisiensi Operasi [skripsi]. Bogor: Institut Pertanian Bogor.

Wahyudi, E. S. (2010). Perancangan Ulang Tata Letak Fasilitas Produksi di CV Dimas Rotan Gatak Sukoharjo. Surakarta, Indonesia: Universitas Sebelas Maret. 